\title{
ALGUNOS DESAFÍOS CONTEMPORÁNEOS A LA TOLERANCIA DEMOCRÁTICA.
}

\author{
Jaime Moreno Garrido \\ Centro de Estudios Judaicos \\ Facultad de Filosofía y Humanidades \\ Universidad de Chile \\ jaimor1@hotmail.com
}

\section{RESUMEN.}

La tolerancia democrática se ve sometida a frecuentes tests. Por ejemplo: Una agrupación neonazi solicita autorización para celebrar un Congreso: ¿Cuál es la reacción democrática correcta? ¿Debe la legislación democrática aceptar todas las organizaciones religiosas que aparecen en la sociedad? ¿Cuál es la respuesta correcta para la cuestión de la llamada "píldora del día después"? ¿o para la discusión de los matrimonios homosexuales?

Pues bien, estas solicitaciones hacen necesaria la reflexión sobre los límites de la tolerancia democrática.

Este trabajo se preocupa de un fenómeno menor, pero que - considerado semióticamente - resulta interesante: Trata las intervenciones más o menos transgresoras que alteran diversas actividades ciudadanas con resultado de represión y/o castigo: encapuchados que desordenan el quehacer académico, deudores habitacionales que alteran actos protocolares, los más o menos cariñosamente llamados "pingüinos", capaces de paralizar el centro de la ciudad, y otras irrupciones semejantes.

Este trabajo pregunta: ¿Qué significan estas manifestaciones? No pregunta sobre sus causas sociales o psicológicas ni ofrece propuestas de soluciones. Su finalidad es modesta: proponer una "lectura" semiótica y un esbozo de interpretación de los desafíos o tests señalados.

\section{PALABRAS CLAVE}

Tolerancia democrática - Trasgresión - Significado de la trasgresión.

\begin{abstract}
Democratic tolerance is often pressed by different tests. For instance: A neonazi organization asks official permission for a public convention: Which is the correct democratic answer? Still other questions: Must democratic laws accept every religious association within the society that they rule? What is the right answer to questions posed by the so-called "next day pill"? or by the proposed discussion about homosexual weddings?

Such solicitations urge reflection about the boundaries of democratic tolerance.

This work deals with a phenomenon that, though a minor one, becomes of interest when is semiotically considered. It views transgressive activities that disturb different urban activities which end in repression and/or punishment: "hooded guys" that dismantle the academic order, public debtors that alter official public solemnities, students that paralyze the city Centrum and different intrusions of the sort.

The question is not about the causes neither about solutions that can be afforded but about the meaning of such manifestations. The aim is limited to propose a semiotic reading and an interpretation's exercise of these challenges or tests.
\end{abstract}

KEY WORDS.

Democratic tolerance - Transgression - Meaning of transgression. 


\section{Descripción de los desafíos}

Comenzaré evocando imágenes que, probablemente, todos tenemos en nuestras memorias y que, me parece, ilustran suficientemente lo que propongo como desafíos y tests de la tolerancia democrática y de su autodefensa.

- La "celebración" del Día del Joven Combatiente.

- Las irrupciones de los Deudores Habitacionales, trasgresoras del protocolo de varios actos oficiales, sobre todo de la Presidenta de la República.

- Las periódicas apariciones de encapuchados que, en distintas Universidades, interrumpen el orden público de las actividades académicas.

- Los recolectores de basura en huelga que arrojaron una tonelada de desperdicios ante La Moneda.

Destaco, además, dos "flashes" que me impresionaron fuertemente por su alta capacidad significativa:

- El poblador "pilucho", desnudo, quien, desde detrás de una malla de alambre, enfrentó al entonces Presidente Lagos".

- Uno de los buses llamados "enchulados" o seudomodernizados que, perdiendo su recubierta blanco-verde, comenzaba a mostrar el originario color amarillo.

Concluyo estas evocaciones con algunos hechos que corren por cuenta ya de las autoridades y sus aláteres, ya de los disidentes:

- Los comportamientos de las empresas concesionarias de carreteras al momento de construir el acceso Santiago-Sur y el túnel del San Cristóbal.

- Las "explicaciones" dadas por voceros que se desmarcan de los desbordes multitudinarios ("Fueron infiltrados", "No son universitarios; vienen de fuera") y la actitud de representantes estudiantiles y funcionarios que apoyan sin apoyar las incursiones de los encapuchados porque las "comprenden".

- Reportajes radiales y televisivos muestran las distintas reacciones de la policía ante desbordes callejeros: Reaccionan de cierta manera ante los jóvenes que "carretean", fiestean o pelean en la Plaza San Enrique de Las Condes o ante los "hinchas" importantes de la UC (= los que pagan las aposentadurías caras del Estadio San Carlos de Apoquindo), y de un modo radicalmente distinto ante los jóvenes que "carretean" o pelean en sectores menos acomodados o ante las barras de los estadios más populares de Pedrero o Santa Laura.

La lista puede alargarse ad infinitum. Estimo que ésta baste para encuadrar el objetivo perseguido en esta comunicación: ¿Qué significan tanto esas irrupciones como las reacciones que provocan?

Dos observaciones aún:

a) Me preocupo en primerísimo lugar de aquellas alteraciones menores e informales del Orden Público, las que parecen inexplicables o inmotivadas (rayados de buses, destrucción de avisos luminosos, de paraderos de buses, etc.). Más atrás ubico aquéllas que, con finalidades claras, desconciertan cuidados actos oficiales. Relego al margen del horizonte tanto las riñas callejeras, los asaltos y actos semejantes que no afectan a lo oficial como las manifestaciones sindicales o de otras organizaciones socialmente reconocidas.

\footnotetext{
${ }^{1}$ En un reportaje hecho por TVN en ocasión del término de su mandato, el ex Presidente la recordó como una de las anécdotas más graciosas de las que le ocurrieron durante su período.
} 
b) No me pregunto por las causas de estos fenómenos ni mucho menos pretendo diseñar soluciones. Mi enfoque es mucho más modesto: Intento sólo proponer una. "lectura" semiótica y un esbozo de interpretación de los desafíos o tests señalados.

\section{Hacia la lectura de los desafíos: la propuesta de Jurij Lotman}

\section{1.- DESCRIPCIÓN DEL MODELO LOTMANIANO.}

1.1.- Lotman estima que, como todo estudio, también el de la cultura, comienza por la descripción. Las culturas que toman conciencia de sí mismas y quieren ubicarse en un concierto más amplio, se (auto)describen.

Quienes generan estas (auto)descripciones son las capas centrales, nucleares de la sociedad y, al hacerlo, tienden espontáneamente a privilegiar los elementos y las relaciones invariables del sistema. "Es precisamente esta estructura invariante la que constituye, para una descripción de este tipo, la única realidad" (Lotman 1979, Pág. 95). Los elementos o relaciones inestables, irregulares, "lo que no calza" es descartado justamente por ser extrasistémicos, y por ende, es considerado quantité négligeable y queda sustraído al pensamiento analítico.

Consecuencia: las descripciones ofrecen modelos simplificados y sobreorganizados. La consistencia aparece mucho más rígida de lo que es en realidad. "La repulsa a describir lo extrasistémico, su expulsión más allá de los límites de la ciencia suprime una reserva dinámica y tiene como efecto presentarnos el sistema estudiado bajo un aspecto que excluye, por principio, todo juego entre homeostasis y evolución" (Lotman 1979, Pág. 97). Incluso, "la marca de <inexistencias (es decir, de extrasistematicidad) parece ser simultáneamente la marca de lo extrasistémico (desde el punto de vista interior del sistema) y el índice negativo de las marcas estructurales del sistema mismo" (Lotman 1979, Pág. 98) ${ }^{2}$.

Nos encontramos entonces con la ilusión de una totalidad altamente organizada, espejismo exacerbado y legitimado por el metalenguaje principalmente jurídico y religioso desarrollado por el sistema. Tal metalenguaje puede rigidizarse hasta el extremo "de perder casi todo contacto con los sistemas reales que pretende describir. Sin embargo, goza, aún en esas circunstancias, de la autoridad de su <corrección > y de su <existencia real>, mientras que las capas reales de la semiosis social pasan enteramente al dominio de lo <incorrecto> y de lo <inexistente>"(Lotman 1979, Pág. 98). Lotman quiere describir la cultura recuperando el dinamismo del sistema generado por la tensión con lo extrasistémico. Para ello diseña y sigue una estrategia.

1.2.- Heredero de tradiciones anteriores, comienza con la propuesta de "examinar la totalidad de los textos que constituyen la cultura desde dos puntos de vista: una comunicación determinada y el código mediante el cual se descifra dicha comunicación en el texto.

El análisis de la cultura desde este punto de vista nos asegura que es posible describir los diversos tipos de cultura como tipos de lenguajes particulares y que, de esta manera, pueden aplicárseles los métodos usados en el estudio de los sistemas semióticos" (Lotman 1979, Pág. 41).

Al hacerlo, no se contenta con usar sola o preferentemente los instrumentos de la lingüística tradicional sino que introduce además los aportes del modelo informático.

Véase el siguiente esquema que, a mi juicio expresa con suficiente claridad la propuesta lotmaniana:

\footnotetext{
${ }^{2}$ Es importante la terminología usada en las descripciones. La denominación de los procesos influye sobre la manera de verlos; los nombres impuestos cambian la percepción de la realidad y el carácter de la conducta (Ver Lotman 2000, Pág. 197). El vocabulario sistémico que llama a los actantes extrasistémicos: "bandas", "hordas", "grupúsculos", "desadaptados", etc. muestra el papel creativo de realidad que poseen los nombres.
} 


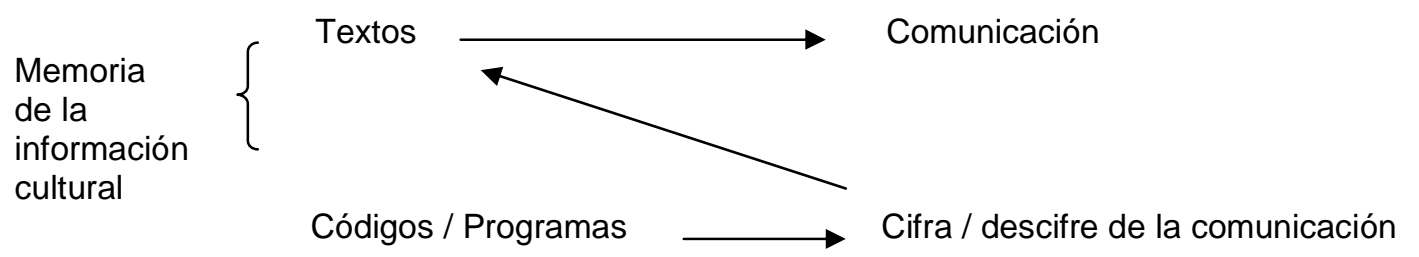

En este esquema,

texto cultural es cualquier comunicación registrada dentro de un sistema sígnico: "Desde este punto de vista, podemos hablar de un ballet, de un espectáculo teatral, de un desfile militar y de todos los demás sistemas sígnicos de comportamiento como de textos, en la misma medida en la que aplicamos este término a un texto escrito en una lengua natural, a un poema o a un cuadro". (Lotman 1979, p. 41 n.2);

Código / programa cultural ${ }^{3}$ es un sistema complejo de modelización o estructuración humana del universo. "La cultura es un generador de estructuralidad; es así como crea alrededor del hombre una socioesfera que, al igual que la biosfera, hace posible la vida, no orgánica, obviamente, sino de relación" (Lotman 1979, Pág. 70).

El desafío que, según Lotman, enfrenta el intérprete de la cultura es encontrar el / los códigos y programas que permiten tanto el desciframiento como la producción de los textos culturales.

Según el modelo, los hechos transgresores que hemos citado al inicio son "textos": ¿Qué código / programa de fondo los sostiene?

1.3.- En el intento por recuperar el dinamismo latente en lo oculto, escamoteado por las descripciones más bien inertes de lo regular, Lotman instala y desarrolla pares de opuestos que le permiten calibrar tanto el equilibrio como la tensión, tanto lo considerado correcto y normal como lo incorrecto y trasgresor.

Así opone y complementa

\section{Homeostasis}

Sistémico

Unívoco

Núcleo

Descrito

Indispensable

Normado

\section{Dinamismo}

Extrasistémico

Ambivalente

Periferia

No descrito

Superfluo.

Catastrófico ${ }^{4}$

A su juicio, es la tensión entre ambos polos quien produce los cambios culturales; ella es una de las fuentes del dinamismo de los sistemas. Aquí interviene la noción de límite.

\section{2.- LA NOCION DE LÍMITE.}

El tratamiento que Jurij Lotman hace del límite me ha resultado extremadamente seductor y creo que ofrece excelentes sugerencias para leer los tensos dinamismos de la dupla sistémico - extrasistémico.

\footnotetext{
3 Según Lotman, la diferencia entre "código" y "programa” es funcional.

${ }^{4}$ Lotman 2000 trata esta última dupla. Ver principalmente Págs. 195-197.
} 
"Toda cultura, escribe nuestro autor, comienza dividiendo el mundo entre "su propio" espacio interno y el espacio externo de "ellos". La interpretación de esta división binaria depende de la topología de cada cultura. Pero la división efectiva es uno de los universales culturales. El límite puede separar vivos de muertos, sedentarios de nómadas, ciudad de llanuras; puede ser una frontera estatal o social, o nacional, confesional o cualquier otro tipo de frontera" (Lotman 1990 p. 131).

Hay un borde, pues. Pero él no solo posibilita distinguir lo sistémico de lo extrasistémico.

"La noción de límite es ambivalente: separa y al mismo tiempo une: Siempre es el límite de algo y, por lo tanto, pertenece a ambas culturas de frontera, a ambas semiosferas contiguas. El límite es bilingüe y polilingüe. El límite es un mecanismo para trasladar / traducir textos de una semiótica ajena a ."nuestro" lenguaje, es el lugar donde lo que es "externo" se transforma en "interno", es una membrana filtro que transforma los textos extraños de tal manera que pueden llegar a ser parte de la semiótica interna de la semiosfera, incluso cuando retienen sus características propias" (Lotman 1990 p. 136 s.).

Justamente porque separados, es posible establecer un "intercambio osmótico" entre lo sistémico y extrasistémico.

Aparte la metáfora de "la membrana filtro", Lotman emplea la del espejo para ilustrar la función del límite. Escribe: "El mecanismo especular que forma las parejas simétrico-asimétricas está tan ampliamente difundido en todos los mecanismos generativos de sentido, que podemos decir que es universal, abarcador del nivel molecular y de las estructuras generales del universo, por una parte, $y$ de las creaciones globales del espíritu humano, por otra. Para los fenómenos definibles mediante el concepto "texto", es, indiscutiblemente, universal.... Desde luego, todas estas simetrías-asimetrías no son más que mecanismos de generación de sentido, y, del mismo modo que la asimetría bilateral del cerebro humano, al caracterizar el mecanismo del pensamiento no predetermina el contenido de éste, ellas determinan la situación semiótica, pero no el contenido de tal o cual mensaje”. (Lotman, 1996, pp. $21-42)^{5}$.

Veremos qué partido podemos sacar de estas propuestas para la lectura de nuestros textos.

\section{Propuesta de lectura de los "textos" - tests.}

Vuelvo, entonces, a la lectura de las intervenciones más o menos transgresoras, más o menos inmotivadas, que alteran diversas actividades ciudadanas. La pregunta es: ¿Qué significan esas irrupciones?

Leídas con el prisma lotmaniano, habrá que considerarlas como enfrentamientos especulares de textos sígnicos.

Veamos distintos niveles de oposiciones.

a) Los actantes:

\section{SISTEMICO}

La autoridad garante del orden

La gente decente

Los que tienen qué perder

\section{EXTRASISTÉMICO}

Las turbas semianárquicas

Los delincuentes y drogadictos

Los que nada tienen que perder

\footnotetext{
${ }^{5}$ Lotman trata latamente el "efecto espejo", en particular la necesidad de aprender a ver y leer al revés (la imagen refleja la izquierda a la derecha, la escritura en espejo, los palíndromos especulares, etc.).

El tema del espejo evoca inevitablemente el tratamiento de "la mimesis" realizado por René Girard. Me permito remitir a mi artículo "Mito, Religión y Violencia" EN: Segundas Jornadas Interdisciplinarias "Religión y Cultura", Fac. de Filosofía y Humanidades - Fac. de Ciencias Sociales, Universidad de Chile, 1993, Págs. 16-31.
} 


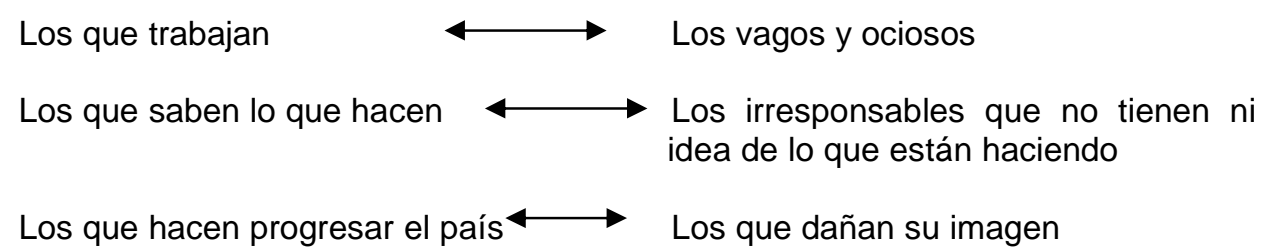

b) Valores puestos en juego:

\section{SISTEMICO}

Orden

Limpieza

Progreso

Tranquilidad

Trabajo

Legalidad

Pureza

\section{EXTRASISTÉMICO}

Caos

Suciedad

Barbarie

Miedo

Ociosidad

Criminalidad

Impureza

A las oposiciones léxico-sintácticas les siguen las oposiciones rituales, es decir, gestos y "aclamaciones" sociales previsibles y que hasta se producen en tiempos fijados 6 .

Propongo leer estos textos como "choque de signos".

Ante signos inquietantes, el sistema, emite miméticamente, especularmente, otros que, en general, se restringen a lo represivo y castigador. La respuesta "en espejo" va desde la descalificación y condena verbal hasta la represión de hecho por medio de la fuerza pública y la aplicación de la legislación penal (incluyendo la Ley de Seguridad Interior del Estado). Signo importante de esta dinámica fue la modificación de la legislación penal (rebaja de la edad para la responsabilidad penal) ${ }^{7}$ cuando cierto tipo de desbordes resultó inimputable gracias a la minoría de edad.

Me parece posible sostener que los "textos" de los enfrentamientos son producto de un "programa" que, con Lotman, llamaré "asimetría simétrica de percepción": Los extrasistémicos, como en una cámara oscura, perciben invertida la imagen de cuanto el sistema califica como Orden, Limpieza, Progreso, Tranquilidad, Trabajo, Legalidad, Pureza. Desordenar, ensuciar, romper y manchar lo ordenado, limpio, íntegro y puro significa que tal "Orden" no es sino apariencia y fachada que escamotea y oculta otro desorden, suciedad, retroceso, inseguridad, injusticia e impureza quizás

\footnotetext{
${ }^{6}$ Ver anexo.

Nuestros extrasistémicos han logrado introducir el Día del Joven Combatiente en el calendario nacional. Y todos sabemos en la Universidad cuándo se abre la temporada de la capucha y en qué días y en qué horario es previsible su irrupción (aunque últimamente ha habido alteraciones del horario...).

${ }^{7}$ Hay datos que muestran a Chile como uno de los países con mayor tasa de población encarcelada.

En cuanto a los disciplinadores sociales, sería interesante considerar - además de los evidentes (Gobierno Interior, Policía y Poder Judicial) - otros que lo son menos. Creo que, colateralmente, el sistema económico funciona como disciplinador: quien contrae un crédito debe "portarse bien", "cuidar la pega"... y jay de él si cae en la base de datos de DICOM! Otros disciplinadores importantes son los Medios de Comunicación Social.
} 
mucho más sobrecogedora ${ }^{8}:$ La percepción de Orden y Caos es, pues, simétrico-asimétrica. En este contexto, el lema "Orden y Patria" (en esa secuencia) de nuestra Policía convierte a la fuerza pública en adversario sígnico natural ${ }^{9}$.

Y aquí, gracias a lo especular, se puede leer la lucha en torno a uno de nuestros más importantes componentes sígnicos: "la imagen del país".

Entre los valores más apreciados y cuidados por el sistema del Orden Ciudadano está la limpieza, la pureza de "la imagen del país", del ícono de la sociedad".

Los elementos extrasistémicos, iconoclastas de nuevo cuño, ponen en vilo esa limpieza y pureza. Mancillarla, significa que la tal "imagen pura" es exactamente eso: una imagen no tan pura, imagen ajena y que no merece tanta devoción ${ }^{11}$. De hecho, su culto tiene la obvia finalidad de obtener favores para la red económica: atraer capitales, fomentar la exportación, elevar el PIB y el ingreso per cápita, en fin, "insertarse en las ligas grandes", como se suele decir.

Sucede, pues, que no hemos logrado componer una red compartida de "signos de orden".

Entonces ¿debe la democracia tolerar los "desbordes" señalados? ¿Tiene que aceptar que junto al tiempo de construir y limpiar hay otro de romper y ensuciar?

No por cierto. Pero una democracia sana no puede contentarse con soluciones autoritarias y represivas.

Concluyo.

Vivimos tensionantes relaciones entre lo sistémico y lo extrasistémico. Esta dinámica urge el "reformateo" del programa que produce textos de enfrentamiento. Pero, Lotman nos ha dejado advertido que los sistemas tienden a la inercia y que los cambios se producen gracias a las presiones de lo extrasistémico.

\footnotetext{
${ }^{8}$ Larga es la lista de tapaderas u ocultamientos de suciedad y de impureza. Abarca desde muros más o menos presentables que invisibilizan casuchas infectas hasta vestimentas elegantes, títulos rimbombantes y cargos públicos importantes que albergan robos, fraudes y trampas al Estado o a la sociedad.

En este contexto, la revisión del léxico eufemístico chileno es altamente ilustrativa. Tanto para tomar un ejemplo aparentemente inocuo, cito la (transversalmente compartida) tapadera lingüística "viveza del chileno" que neutraliza, con dudoso humor, toda clase de trampas.

Y es obvia la osmosis mimético-especular que funciona a través del límite que separa y une lo sistémico con lo extrasistémico:

- honrados ciudadanos colaboran con el comercio clandestino y "pirata" en el centro de Santiago;

- $\quad$ jovencitos de clases acomodadas acuden a los barrios bravos a comprar droga;

- $\quad$ elegantes residentes de barrios top de Santiago emulan (con técnicas más sofisticadas, por supuesto) a los más decadentes ladrones de electricidad de los barrios marginales;

- barras de clubes "cuicos" imitan los comportamientos de las de los más populares y "rascas";

- Señoras respetables compiten con las marginales "mecheras" cuando roban en Alto Las Condes cambiando la rotulación de los productos caros

- flaites cuicos emulan a los flaites-flaites ... Por aquí se cuela un enorme etcétera.
}

Ya he señalado la asimétrica reacción de las fuerzas de orden.

${ }^{9}$ En ciertos momentos, las calles de Santiago fueron escenario de enfrentamientos entre grupos ciudadanos de signos opuestos... y la policía estaba entre ellos. Hoy quedan sólo dos bandos: La policía que defiende el Orden y las "turbas descontroladas" que lo amenazan.

\footnotetext{
${ }^{10}$ Me parece perceptible que el "culto de la Patria" ha ido perdiendo relevancia en beneficio del "culto de la Imagen del País". Es que a la hora de "entrar en las ligas grandes", es mucho más productivo el simbolismo de la "Imagen País" que no el de la "Patria" (Ver Marina JUÁREZ DE ORTIZ, "EI discurso de la ciudad en la era de la globalización", EN M. ECKHOLT - J. SILVA (Eds.), Ciudad y Humanismo. El desafío de convivir en la aldea global. ICAL - UC. del Maule, Talca, 1999. Págs. 15-32).

Hace muy poco supe que, en el organigrama de la administración del Estado, existe un Departamento "Imagen País", presidido (al momento de escribir estas páginas) por Dn. Juan Gabriel Valdés (Ver Miguel PAZ, "Locos por el New York Times", El Mostrador 4 de abril de 2008).

${ }^{11}$ Se ha hecho común entre nosotros la denuncia por desprestigio de o daño a la imagen de las personas o del país. Creo que fue el recordado fiscal Torres Silva quien hizo las primeras denuncias formales y hasta incoó procesos por "asesinato de imagen".
} 
No creo, por lo tanto, que sea demasiado aventurado prever que aún por largo tiempo estaremos editando "textos" - signos de enfrentamiento, pues, no parece que haya, por lo menos a corto plazo, voluntad política para emprender una reforma sustantiva de un sistema tan "amarrado y bien amarrado". Nos lo advirtió un ex Presidente: "Tengan cuidado los que andan diciendo que el sistema está agotado".

Y en este mundo tan estrechamente interconectado, es quizás imposible que un pequeño Estadocliente pueda emprender demasiados cambios por su cuenta. El periplo chino de la Presidenta muestra que la semiosfera global es más fuerte. 


\section{Anexo.}

RITUALIDAD DE LAS MANIFESTACIONES EXTRASISTÉMICAS.

\begin{tabular}{|c|c|c|}
\hline & SISTEMA & EXTRASISTEMA \\
\hline DÍAS PREVIOS & $\begin{array}{l}\text { Anuncios de adopción de medidas de } \\
\text { seguridad. } \\
\text { Llamados a la calma y a manifestar dentro } \\
\text { del orden. }\end{array}$ & $\begin{array}{l}\text { Convocatorias } \\
\text { Desafíos menores a la policía }\end{array}$ \\
\hline $\begin{array}{l}\text { DÍA DE LA } \\
\text { CONVOCATORIA: } \\
\text { mañana }\end{array}$ & $\begin{array}{l}\text { "La ciudad está en orden, dentro de lo } \\
\text { esperado" } \\
\text { "Se actuará con las herramientas legales" } \\
\text { Actuación de la fuerza policial }\end{array}$ & $\begin{array}{l}\text { Marchas no autorizadas } \\
\text { Quiebres in crescendo de las rutinas diarias }\end{array}$ \\
\hline ca. $10.30 \mathrm{am}$ & Primeros detenidos & \\
\hline a media tarde & $\begin{array}{l}\text { Actuación de la fuerza policial } \\
\text { Rumores o anuncios del retiro de la } \\
\text { locomoción colectiva } \\
\text { Rumores o anuncios de interrupción de la } \\
\text { jornada laboral }\end{array}$ & Enfrentamientos mayores \\
\hline $\begin{array}{l}\text { al oscurecer y por } \\
\text { la noche }\end{array}$ & $\begin{array}{l}\text { Retiro a los domicilios particulares } \\
\text { Actuación intensa de la fuerza policial } \\
\text { (Retiro de la locomoción colectiva) } \\
\text { Policías heridos o contusos (Visitas } \\
\text { protocolares) } \\
\text { Reportajes televisivos. } \\
\text { Las autoridades condenan los desbordes. }\end{array}$ & $\begin{array}{l}\text { Fogatas, barricadas, cortes de calles en } \\
\text { barrios de clase media y en poblaciones. } \\
\text { Detenidos, heridos. Eventuales muertos }\end{array}$ \\
\hline $\begin{array}{l}\text { DÍA(S) } \\
\text { SIGUIENTE(S) }\end{array}$ & $\begin{array}{l}\text { Balance cuantitativo de lo sucedido. } \\
\text { Incriminación de "los otros". } \\
\text { Defensa del proceder de la policía. } \\
\text { "Se aplicará el máximo rigor de la ley" }\end{array}$ & $\begin{array}{l}\text { Incriminación de "los otros". } \\
\text { Denuncia y condena del proceder de la } \\
\text { policía. }\end{array}$ \\
\hline
\end{tabular}




\section{BIBLIOGRAFÍA DE JURIJ LOTMAN EMPLEADA EN ESTE TRABAJO.}

Jurij LOTMAN, "El problema del signo y del sistema sígnico en la tipología de la cultura anterior al siglo XX", EN: Jurij M. Lotman y la Escuela de Tartu, Semiótica de la cultura, Ed. Cátedra, Madrid, 1979. Págs. 41-66.

Jurij M. LOTMAN y Boris A. USPENSKIJ, "Sobre el mecanismo semiótico de la cultura", EN: Jurij M. Lotman y la Escuela de Tartu, Semiótica de la cultura, Ed. Cátedra, Madrid, 1979. Págs. 67-92.

Jurij M. LOTMAN, "Un modelo dinámico del sistema semiótico" EN: Jurij M. Lotman y la Escuela de Tartu, Semiótica de la cultura, Ed. Cátedra, Madrid, 1979. Págs. 93-108.

Yuri M. LOTMAN, "The notion of boundary", EN: Universe of Mind. A Semiotic Theory of Culture. Indiana University Press, 1990. Págs. 131-142.

Iuri M. LOTMAN, "Acerca de la semiosfera”, EN: La Semiosfera I. Semiótica de la cultura y del texto (Selección y traducción del ruso por Desiderio Navarro), Cátedra, Universitat de Valencia, 1996, Págs. 21-42.

luri M. LOTMAN, "Sobre la dinámica de la cultura", EN: La Semiosfera III. Semiótica de las artes y de la cultura (Selección y traducción del ruso por Desiderio Navarro), Cátedra, Universitat de Valencia, 2000, Págs. 194-214. 